\title{
Synthesis of Hyperbranched Poly(ester)s with Pendant Hydroxy Groups by the Polyaddition of Bis(oxetane)s with 1,3,5-Benzenetricarboxylic Acid
}

\author{
Tadatomi NishiKubo, ${ }^{\dagger}$ Hiroto Kudo, and Takehiko NAKAGAMI \\ Department of Applied Chemistry, Faculty of Engineering, Kanagawa University, \\ Rokkakubashi, Kanagawa-ku, Yokohama 221-8686, Japan
}

(Received September 5, 2005; Accepted October 4, 2005; Published February 15, 2006)

\begin{abstract}
Hyperbranched poly(ester)s with many pendant primary hydroxy groups were prepared in 21$84 \%$ yields by polyadditions of certain bis(oxetane)s such as 1,4-bis[(3-ethyl-3-oxetanylmethoxymethyl)]benzene (BEOB), 1,2-bis[(3-ethy-3-oxetanyl)methoxy]benzene (1,2-BEOMB), 1,3-bis[(3-ethy-3-oxetanyl)methoxy]benzene (1,3-BEOMB), 1,4-bis[(3-ethy-3-oxetanyl)methoxy]benzene (1,4-BEOMB), 4,4'-bis[(3-ethyl-3-oxetanyl)methoxy]biphenyl (4,4'-BEOBP), 3,3',5,5'-tetramethyl-[4,4'-bis(3-ethyl-3-oxetanyl)methoxy]biphenyl (TM-BEOBP) with 1,3,5benzenetricarboxylic acid (TMA) using tetraphenylphosphonium chloride (TPPC) as a catalyst in NMP at $140{ }^{\circ} \mathrm{C}$ for $12 \mathrm{~h}$. Resulting polymers were insoluble in water; however, these polymers were soluble in $2.3 \%$ tetramethylammonium hydroxide aqueous solution. These polymers were also soluble in dioxane, THF, MEK, and aprotic polar solvents. The glass transition temperatures $\left(T_{\mathrm{g}} \mathrm{s}\right)$ of these polymers were $59-131^{\circ} \mathrm{C}$. [DOI $10.1295 /$ polymj.38.145]

KEY WORDS Synthesis of Hyperbranched Poly(ester) / Pendant Hydroxy Group / Polyaddition / Bis(oxetane) / 1,3,5-Benzenetricarboxylic Acid /
\end{abstract}

Oxetanes as 4-membered cyclic ether have almost the same strain energy ${ }^{1}(107 \mathrm{~kJ} / \mathrm{mol})$ as 3 -membered cyclic ether oxiranes. Furthermore, basicities of oxetanes were generally higher than those of oxiranes. Therefore, numerous studies ${ }^{2}$ of the cationic polymerization of oxetane compound have been reported. The first commercial polymer of oxetane was PENTONE ${ }^{\circledR}$, which was prepared by the ring-opening polymerization of 3,3-bis(chloromethyl)oxetane. Very recently, Motoi and his coworkers ${ }^{3-5}$ found certain cationic isomerization reactions of oxetane compounds.

However, any other useful ring-opening reactions of oxetane have not been reported excepting our recent research works. ${ }^{6}$ Since more than 15 years ago, my research group have studied the development of new ring-opening addition reaction of oxetane and succeeded in finding new reactions of oxetanes such as ringopening addition reactions with acyl chlorides, ${ }^{7}$ phosphonyl chlorides, ${ }^{8}$ silyl chloride, ${ }^{9}$ active esters, ${ }^{7}$ carboxylic acids, ${ }^{10}$ phenols, ${ }^{11,12}$ and thiols ${ }^{13}$ using appropriate quaternary onium salts or crown ether complexes as catalysts. These reactions can be applied practically to the polyadditions of bis(oxetane)s with above reagents such as diacyl chlorides, ${ }^{14-17}$ phosphonyl dichlorides, ${ }^{8}$ active diesters, ${ }^{18,19}$ dicarboxylic acids, ${ }^{10}$ bisphenols, ${ }^{11,12}$ and dithiols ${ }^{13}$ to afford corresponding polymers with high molecular weights. Recently, we also found that an anionic ring-opening polymerization of 2-(hydroxymethyl)oxetanes produced corresponding hyperbranched poly(ether)s con- taining one terminal oxetanyl groups and many pendant primary hydroxy groups using the complex of potassium $t$-buthoxide with crown ether as a catalyst system, ${ }^{20-22}$ and an anionic ring-opening alternating copolymerization $^{23}$ of oxetanes with cyclic carboxylic anhydrides using certain quaternary onium salts as catalysts.

The above reaction systems of oxetane compounds and the oxetane polymers prepared by the reactions seem to have great possibility as an important key technology in coatings and electronics fields, and polymer industry in general.

Meanwhile, hyperbranched polymers (HBPs) have recently attracted a great deal of attention as one of the dendritic macromolecules, which have lower viscosity, good solubility and many reactive terminal groups compared with the corresponding linear ones. ${ }^{24}$ There are many synthetic methods for the preparation of the HBPs, such as vinyl polymerization $^{25}$ and ring-opening polymerization ${ }^{26}$ accompanying suitable chain transfer reaction. Furthermore, although HBPs are prepared by the step-wise polymerizations such as polycondensations and polyadditions, in which there are two differential methods; one is the self-condensation ${ }^{24}$ (or -addition) reaction of $\mathrm{AB}_{2}$ monomers, however, these monomers are not always commercially available. Another is the polycondensation (or polyaddition) reaction of $\mathrm{A}_{2}$ type monomer with $\mathrm{B}_{3}$-type monomer. ${ }^{27,28}$ The latter method is practically advantageous in industrial appli-

${ }^{\dagger}$ To whom correspondence should be addressed (E-mail: nishikubot@kanagawa-u.ac.jp). 

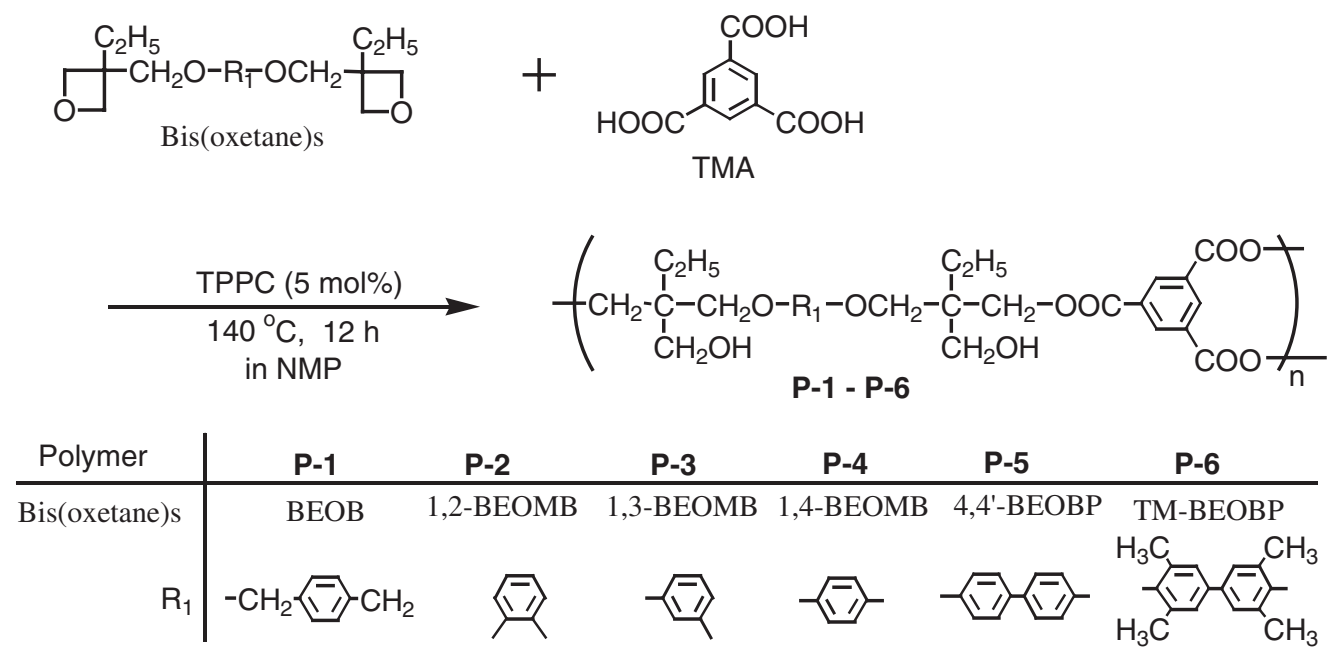

Scheme 1.

cations, because numerous number of monomers are commercially available.

From these backgrounds, in this article, the authors examined the polyaddition of bis(oxetane)s with active 1,3,5-benzenetricarboxylic acid (TMA) for the synthesis of hyperbranched poly(ether)s containing pendant primary hydroxy groups under appropriate reaction conditions (Scheme 1).

\section{EXPERIMENTAL}

\section{Materials}

The reaction solvents, such as $o$-dichlorobenzene, sulfolane, $N$-methylpyrrolidone (NMP), $N, N$-dimethylacetamide (DMAc), dimethyl sulfoxide (DMSO), and hexamethylphosphorictriamide (HMPA) were dried with $\mathrm{CaH}_{2}$, and purified by distillation before use. Anisole was dried with $\mathrm{Na}$ wire, and purified by distillation before use. Tetrabutylamminoum bromide (TBAB) was recrystalized twice from ethyl acetate. Reagents grade 1,3,5-benzenetricarboxylic acid (TMA), tetrabutylamminoum chloride (TBAC), tetrabutylphosphonium bromide (TBPB), tetrabutylphosphonium chloride (TBPC), tetraphenylphosphonium chloride (TPPC), tetraphenylphosphonium bromide (TPPB), tetraphenylphosphonium iodide (TPPI), 18-crown-6 (18-C-6), potassium chloride $(\mathrm{KCl})$, potassium bromide $(\mathrm{KBr})$, and lithium hydroxide $(\mathrm{LiOH})$ were dried in vacuo, and used without further purification. Bis(oxetane)s, 1,4-bis[(3-ethyl-3-oxetanylmethoxymethyl)]benzene (BEOB), 1,2-bis[(3-ethy-3-oxetanyl)methoxy]benzene (1,-BEOMB), 1,3-bis[(3-ethy-3-oxetanyl)methoxy]benzene (1,3-BEOMB), 1,4-bis[(3-ethy-3-oxetanyl)methoxy]benzene (1,4-BEOMB), 4,4'-bis[(3-ethyl-3-oxetanyl)methoxy] biphenyl (4,4'-BEOBP), 3,3',5,5'-tetramethyl-[4,4'-bis(3-ethyl-3-oxetanyl)methoxy]biphenyl (TM-BEOBP) were donated from Toagosei Co., Ltd. and were purified by recrystallization from appropriate solvents.

\section{Measurement}

Melting points were determined with a Yanako MP500D hot-stage microscope. Infrared (IR) absorption spectra were measured on a Jasco model FT IR-420 spectrometer. The NMR spectra were recorded on JNM FX-200 $\left(200 \mathrm{MHz}\right.$ for ${ }^{1} \mathrm{H}$ NMR and $50 \mathrm{MHz}$ for ${ }^{13} \mathrm{C}$ NMR) in DMSO- $d_{6}$ with $\mathrm{Me}_{4} \mathrm{Si}$ (TMS) as an internal standard. The number-average molecular weight $\left(M_{\mathrm{n}}\right)$ and weight-average molecular weight $\left(M_{\mathrm{w}}\right)$ of the polymers were estimated by size exclusion chromatography (SEC; TOSOH model HLC8020) on TSK gel Multipore Hxl-M columns calibrated by narrow molecular weight polystyrene standards and with tetrahydrofuran (THF) as an eluent without correction using a refractive index detector. Glass transition temperatures $\left(T_{\mathrm{g}}\right) \mathrm{s}$ were measured on a Seiko Electronic Instruments model EXSTAR 6000/ DSC6200 differential scanning calorimeter (DSC) at a heating rate of $10{ }^{\circ} \mathrm{C} / \mathrm{min}$ under nitrogen atmosphere. Thermal analysis (TGA) was performed on a Seiko Electronic Instruments model EXSTAR 6000/ TG/DTA 6220 at a heating rate of $10^{\circ} \mathrm{C} / \mathrm{min}$ under nitrogen.

Synthesis of Hyperbranched Polymer P-1 by Polyaddition of BEOB with TMA

A typical procedure for the polyaddition of BEOB with TMA is as follows: BEOB $(0.502 \mathrm{~g} ; 1.5 \mathrm{mmol})$, TMA $(0.210 \mathrm{~g} ; 1.0 \mathrm{mmol})$, TPPC $(0.028 \mathrm{~g} ; 0.075$ mmol), and NMP $(1.0 \mathrm{~mL})$ were charged to a glass tube in a dry box, after which the tube was evacuated and sealed using a gas torch. The reaction was performed at $140{ }^{\circ} \mathrm{C}$ for $12 \mathrm{~h}$ in the sealed tube under stirring, and then the tube was opened. The resulting 
solution was diluted with a small amount of THF and poured into water $(200 \mathrm{~mL})$ containing lithium bromide to precipitate the polymer. The resulting polymer was precipitated twice from THF into excess mixed solvent of $n$-hexane and ether (vol./vol. $=1 / 1$ ), and dried in vacuo at $60{ }^{\circ} \mathrm{C}$ for $24 \mathrm{~h}$. The yield of resulting polymer P-1 was $0.60 \mathrm{~g}(84 \%)$. The number-average moleculer weight $\left(M_{\mathrm{n}}\right)$ of the polymer estimated by SEC was $8500\left(M_{\mathrm{w}} / M_{\mathrm{n}}=2.89\right)$. IR (film): $3438(v \mathrm{OH}), 1729(v \mathrm{C}=\mathrm{O}$, ester), $1461(v \mathrm{C}=\mathrm{C}$ of aromatic), 1241 ( $v \mathrm{C}-\mathrm{O}-\mathrm{C}$, ester), 1098 ( $v \mathrm{C}-\mathrm{O}-\mathrm{C}$, ether), $992 \mathrm{~cm}^{-1}$ ( $v \mathrm{C}-\mathrm{O}-\mathrm{C}$, cyclic ether). ${ }^{1} \mathrm{H}$ NMR (200 MHz, DMSO- $d_{6}$, TMS) $\delta=0.74-0.85(\mathrm{~m}, 7.8 \mathrm{H}$, $\left.\mathrm{CH}_{2} \mathrm{CH}_{3}\right), 1.37-1.64\left(\mathrm{~m}, 5.7 \mathrm{H}, \mathrm{CH}_{2} \mathrm{CH}_{3}\right), 3.31-3.53$ (m, $9.2 \mathrm{H}, \mathrm{C}-\mathrm{CH}_{2}-\mathrm{O}$ and $\left.\mathrm{CH}_{2}-\mathrm{OH}\right), 4.23-4.53(\mathrm{~m}$, $12.7 \mathrm{H}, \mathrm{CO}_{2}-\mathrm{CH}_{2}-\mathrm{C}, \mathrm{Ar}-\mathrm{CH}_{2}-\mathrm{O}, \mathrm{C}-\mathrm{CH}_{2}-\mathrm{O}$ in oxetane ring, and $\left.\mathrm{CH}_{2}-\mathrm{OH}\right), 7.12-7.34(\mathrm{~m}, 5.5 \mathrm{H}$, aromatic $\mathrm{H}$ in BEOB unit), 8.51-8.69 ppm (m, 3.0H, aromatic $\mathrm{H}$ in TMA unit).

The structure of the hyperbranched polyester was separated into the following three units, $\mathrm{a}, \mathrm{b}$, and $\mathrm{c}$ (Figure 2) which were calculated from the intensity ratio of proton signal based on $8.51-8.69 \mathrm{ppm}$ protons from TMA unit. Unit ratios of a:b:c = 1:0.24:0.94. The content of the terminal carboxyl groups in the polymer was measured by neutralization titration of the carboxyl groups using $\mathrm{KOH}$ aqueous solution in THF $(0.01 \mathrm{~mol} / \mathrm{L})$. The content of $\mathrm{COOH}$ group was $4.81 \%$.

Synthesis of $\boldsymbol{P}-2$ by Polyaddition of 1,2-BEOMB with TMA

Yield $=21 \% . \quad M_{\mathrm{n}}=2400, \quad M_{\mathrm{w}} / M_{\mathrm{n}}=1.34 . \quad$ Unit ratios of a:b:c $=1: 0.43: 0.95$. The content of $\mathrm{COOH}$ group was $4.31 \%$. IR (film): 3429 ( $v \mathrm{OH}), 1731$ ( $v$ $\mathrm{C}=\mathrm{O}$, ester), $1462(v \mathrm{C}=\mathrm{C}$, aromatic $), 1255(v \mathrm{C}-\mathrm{O}-$ C ester), 1053 ( $v$ C-O-C, ether), $993 \mathrm{~cm}^{-1}$ ( $v$ C-O-C, Cyclic ether). ${ }^{1} \mathrm{H}$ NMR $\left(200 \mathrm{MHz}, \mathrm{DMSO}-d_{6}, \mathrm{TMS}\right)$ $\delta=0.82-1.04\left(\mathrm{~m}, 8.1 \mathrm{H}, \mathrm{CH}_{2} \mathrm{CH}_{3}\right), 1.42-1.93(\mathrm{~m}$, $\left.5.5 \mathrm{H}, \mathrm{CH}_{2} \mathrm{CH}_{3}\right), 3.41-3.78$ (m, 4.7H, $\left.\mathrm{CH}_{2}-\mathrm{OH}\right), 3.78-$ $4.18\left(\mathrm{~m}, 5.5 \mathrm{H}, \mathrm{C}-\mathrm{CH}_{2}-\mathrm{O}\right), 4.18-5.15\left(\mathrm{~m}, 8.0 \mathrm{H}, \mathrm{CO}_{2}-\right.$ $\mathrm{CH}_{2}-\mathrm{C}, \mathrm{C}-\mathrm{CH}_{2}-\mathrm{O}$ in oxetane ring, and $\mathrm{CH}_{2}-\mathrm{OH}$ ), 6.70-7.08 ( $\mathrm{m}, 5.5 \mathrm{H}$, aromatic $\mathrm{H}$ in BEOMB unit), $8.51-8.69 \mathrm{ppm}(\mathrm{m}, 3.0 \mathrm{H}$, aromatic $\mathrm{H}$ in TMA unit).

Synthesis of $\boldsymbol{P - 3}$ by Polyaddition of 1,3-BEOMB with TMA

Yield $=49 \% . \quad M_{\mathrm{n}}=3000, \quad M_{\mathrm{w}} / M_{\mathrm{n}}=1.34$. Unit ratios of a:b:c $=1: 0.26: 1.01$. The content of $\mathrm{COOH}$ group was $4.41 \%$. IR (film): $3424(v \mathrm{OH}), 1730$ ( $v$ $\mathrm{C}=\mathrm{O}$, ester), $1462(v \mathrm{C}=\mathrm{C}$, aromatic $), 1241(v \mathrm{C}-$ O-C ester), 1056 ( $v \mathrm{C}-\mathrm{O}-\mathrm{C}$, ether), $992 \mathrm{~cm}^{-1}(v \mathrm{C}-$ $\mathrm{O}-\mathrm{C}$, Cyclic ether). ${ }^{1} \mathrm{H}$ NMR $\left(200 \mathrm{MHz}\right.$, DMSO- $d_{6}$, TMS) $\delta=0.82-1.04\left(\mathrm{~m}, 7.6 \mathrm{H}, \mathrm{CH}_{2} \mathrm{C}_{3}\right), 1.42-1.93$ (m, 5.1H, $\left.\underline{\mathrm{CH}}_{2} \mathrm{CH}_{3}\right), 3.41-3.78\left(\mathrm{~m}, 4.3 \mathrm{H}, \mathrm{C}_{2}-\mathrm{OH}\right)$,
3.78-4.18 (m, 5.1H, C- $\left.\mathrm{CH}_{2}-\mathrm{O}\right), 4.18-5.15(\mathrm{~m}, 6.7 \mathrm{H}$, $\mathrm{CO}_{2}-\mathrm{CH}_{2}-\mathrm{C}, \mathrm{C}-\mathrm{CH}_{2}-\mathrm{O}$ in oxetane ring, and $\mathrm{CH}_{2}-$ $\mathrm{OH})$, 6.24-6.85 (m, 3.8H, aromatic $\mathrm{H}$ in BEOMB unit), 6.98-7.25 (m, 1.2H, aromatic $\mathrm{H}$ in BEOMB unit), $8.51-8.69 \mathrm{ppm}(\mathrm{m}, 3.0 \mathrm{H}$, aromatic $\mathrm{H}$ in TMA unit).

Synthesis of $\boldsymbol{P}-4$ by Polyaddition of 1,4-BEOMB with TMA

Yield $=53 \% . \quad M_{\mathrm{n}}=4100, \quad M_{\mathrm{w}} / M_{\mathrm{n}}=1.70 . \quad$ Unit ratios of a:b:c $=1: 0.49: 0.88$. The content of $\mathrm{COOH}$ group was 4.14\%. IR (film): $3425(v \mathrm{OH}), 1730(v$ $\mathrm{C}=\mathrm{O}$, ester), 1465 ( $v \mathrm{C}=\mathrm{C}$, aromatic $), 1240(v \mathrm{C}-$ $\mathrm{O}-\mathrm{C}$ ester), 1052 ( $v \mathrm{C}-\mathrm{O}-\mathrm{C}$, ether), $993 \mathrm{~cm}^{-1}$ ( $v \mathrm{C}-$ $\mathrm{O}-\mathrm{C}$, Cyclic ether). ${ }^{1} \mathrm{H}$ NMR $\left(200 \mathrm{MHz}\right.$, DMSO- $d_{6}$, TMS) $\delta=0.82-1.04\left(\mathrm{~m}, 7.4 \mathrm{H}, \mathrm{CH}_{2} \mathrm{CH}_{3}\right), 1.42-1.93$ $\left(\mathrm{m}, 5.5 \mathrm{H}, \mathrm{CH}_{2} \mathrm{CH}_{3}\right), 3.41-3.78\left(\mathrm{~m}, 5.1 \mathrm{H}, \mathrm{CH}_{2}-\mathrm{OH}\right)$, $3.78-4.18\left(\mathrm{~m}, 5.1 \mathrm{H}, \mathrm{C}-\mathrm{CH}_{2}-\mathrm{O}\right), 4.18-5.15(\mathrm{~m}, 7.4 \mathrm{H}$, $\mathrm{CO}_{2}-\mathrm{C}_{2}-\mathrm{C}, \mathrm{C}-\mathrm{C}_{2}-\mathrm{O}$ in oxetane ring, and $\mathrm{CH}_{2}-$ $\mathrm{OH}), 6.70-7.08(\mathrm{~m}, 5.5 \mathrm{H}$, aromatic $\mathrm{H}$ in BEOMB unit), $8.51-8.69 \mathrm{ppm}(\mathrm{m}, 3.0 \mathrm{H}$, aromatic $\mathrm{H}$ in TMA unit).

Synthesis of $\boldsymbol{P}-5$ by Polyaddition of 4,4'-BEOBP with TMA

Yield $=74 \% . \quad M_{\mathrm{n}}=6200, \quad M_{\mathrm{w}} / M_{\mathrm{n}}=1.74$. Unit ratios of a:b:c $=1: 0.62: 0.97$. The content of $\mathrm{COOH}$ group was $3.77 \%$. IR (film): $3430(v \mathrm{OH}), 1731(v$ $\mathrm{C}=\mathrm{O}$, ester), $1470(v \mathrm{C}=\mathrm{C}$, aromatic $), 1255(v \mathrm{C}-$ $\mathrm{O}-\mathrm{C}$ ester), 1053 ( $v \mathrm{C}-\mathrm{O}-\mathrm{C}$, ether), $993 \mathrm{~cm}^{-1}$ ( $v \mathrm{C}-$ O-C, Cyclic ether). ${ }^{1} \mathrm{H}$ NMR $\left(200 \mathrm{MHz}\right.$, DMSO- $d_{6}$, TMS) $\delta=0.85-1.04\left(\mathrm{~m}, 8.5 \mathrm{H}, \mathrm{CH}_{2} \mathrm{C}_{3}\right), 1.42-1.98$ (m, 56.4H, $\left.\mathrm{C}_{2} \mathrm{CH}_{3}\right), 3.43-3.78\left(\mathrm{~m}, 5.12 \mathrm{H}, \mathrm{C}_{2}-\right.$ $\mathrm{OH}), 3.78-4.18\left(\mathrm{~m}, 5.7 \mathrm{H}, \mathrm{C}-\mathrm{CH}_{2}-\mathrm{O}\right), 4.18-5.35(\mathrm{~m}$, $8.0 \mathrm{H}, \mathrm{CO}_{2}-\mathrm{CH}_{2}-\mathrm{C}, \mathrm{C}-\mathrm{CH}_{2}-\mathrm{O}$ in oxetane ring, and $\left.\mathrm{CH}_{2}-\mathrm{OH}\right), 6.65-7.12(\mathrm{~m}, 5.4 \mathrm{H}$, aromatic $\mathrm{H}$ in BEOBP unit), 7.12-7.64 (m, 5.4H, aromatic $\mathrm{H}$ in BEOBP unit), $8.51-8.69 \mathrm{ppm}(\mathrm{m}, 3.0 \mathrm{H}$, aromatic $\mathrm{H}$ in TMA unit).

Synthesis of $\boldsymbol{P}-6$ by Polyaddition of TM-BEOBP with TMA

Yield $=79 \% . \quad M_{\mathrm{n}}=6900, \quad M_{\mathrm{w}} / M_{\mathrm{n}}=2.14$. Unit ratios of a:b:c $=1: 0.42: 1.03$. The content of $\mathrm{COOH}$ group was 4.16\%. IR (film): $3430(v \mathrm{OH}), 1731$ ( $v$ $\mathrm{C}=\mathrm{O}$, ester), $1474(v \mathrm{C}=\mathrm{C}$, aromatic $), 1238(v \mathrm{C}-$ $\mathrm{O}-\mathrm{C}$ ester), 1066 ( $v \mathrm{C}-\mathrm{O}-\mathrm{C}$, ether), $988 \mathrm{~cm}^{-1}(v \mathrm{C}-$ $\mathrm{O}-\mathrm{C}$, cyclic ether). ${ }^{1} \mathrm{H}$ NMR $\left(200 \mathrm{MHz}\right.$, DMSO- $d_{6}$, TMS) $\delta=0.82-1.04\left(\mathrm{~m}, 8.6 \mathrm{H}, \mathrm{CH}_{2} \mathrm{C}_{3}\right), 1.40-1.95$ $\left(\mathrm{m}, 6.2 \mathrm{H}, \mathrm{CH}_{2} \mathrm{CH}_{3}\right), 1.95-2.38\left(\mathrm{~m}, 16.2 \mathrm{H}, \mathrm{Ar}-\mathrm{CH}_{3}\right)$, 3.43-3.90 (m, 9.4H, $\left.\mathrm{C}_{2}-\mathrm{OH}, \mathrm{C}-\mathrm{C}_{2}-\mathrm{O}\right), 4.02-$ $5.02\left(\mathrm{~m}, 8.6 \mathrm{H}, \mathrm{CO}_{2}-\mathrm{CH}_{2}-\mathrm{C}, \mathrm{Ar}-\mathrm{CH}_{2}-\mathrm{O}, \mathrm{C}-\mathrm{CH}_{2}-\mathrm{O}\right.$ in oxetane ring, and $\left.\mathrm{CH}_{2}-\mathrm{OH}\right), 6.65-7.35(\mathrm{~m}, 6.2 \mathrm{H}$, aromatic $\mathrm{H}$ in TM-BEOBP unit), 8.40-8.98 ppm (m, $3.0 \mathrm{H}$, aromatic $\mathrm{H}$ in TMA unit). 


\section{RESULTS AND DISCUSSION}

Since the polyaddition of bis(oxetane)s with dicarboxylic acids proceeded at $140^{\circ} \mathrm{C}$ to produce corresponding polyesters with high molecular weight, the catalytic effect of the polyaddition of BEOMB with TMA was examined at $140{ }^{\circ} \mathrm{C}$ for $12 \mathrm{~h}$.

When the reaction was performed without any catalyst, oligomer with low molecular weight $\left(M_{\mathrm{n}}=\right.$ 2200 ) was obtained in only $13 \%$ yield. However, the yields and $M_{\mathrm{n}}$ increased using following catalysts. As summarized in Table I, tetraphenyl onium salts such as TPPC, TPPB, and TPPI showed higher cata-

Table I. The polyaddition of BEOB with TMA using certain catalysts ${ }^{\mathrm{a}}$

\begin{tabular}{rlccc}
\hline Run & Catalyst & ${\text { Yield }(\%)^{\mathrm{b}}}$ & $M_{\mathrm{n}} \times 10^{-3 \mathrm{c}}$ & $M_{\mathrm{w}} / M_{\mathrm{n}}{ }^{\mathrm{c}}$ \\
\hline 1 & None & 13 & 2.2 & 1.35 \\
2 & TBAC & 55 & 4.6 & 1.74 \\
3 & TBAB & 53 & 4.0 & 1.88 \\
4 & TBPC & 72 & 5.8 & 2.11 \\
5 & TBPB & 71 & 5.7 & 2.11 \\
6 & TPPC & 84 & 8.5 & 2.89 \\
7 & TPPB & 80 & 7.2 & 2.99 \\
8 & TPPI & 82 & 7.5 & 4.90 \\
9 & $18-C-6 / \mathrm{KCl}$ & 52 & 4.0 & 1.76 \\
10 & $18-C-6 / \mathrm{KBr}$ & 39 & 3.1 & 1.72 \\
\hline
\end{tabular}

${ }^{\mathrm{a}}$ The reaction was carried out with BEOB $(1.5 \mathrm{mmol})$ and TMA $(1.0 \mathrm{mmol})$ using $5 \mathrm{~mol} \%$ of various catalysts in NMP $(1.0 \mathrm{~mL})$ at $140{ }^{\circ} \mathrm{C}$ for $12 \mathrm{~h} .{ }^{\mathrm{b}}$ Insoluble parts in water and $n$ hexane and diethyl ether. ${ }^{c}$ Estimated by GPC (DMF) based on polystyrene standards. lytic activity than other tetrabutyl onium salts such as TBAC, TBAB, TBPB, and TBPB from the view points of molecular weight and yield of the polymer. This may be due to the higher thermal stability ${ }^{29,30}$ of tetraphenyl onium salts than that of tetrabutyl onium salts. However, the activities of complexes of 18-crown-6 with $\mathrm{KCl}$ and $\mathrm{KBr}$ were lower than those of tetraphenyl onium salts. This may be due to the less solubility of the crown ether complexes into the reaction medium.

This means that quaternary onium salts or crown ether complexes, especially tetraphenyl onium salts are appropriate as catalyst for the polyaddition of bis(oxetane) with TMA to form hyperbranched polymer.

The structure of the obtained polymer P-1 was confirmed by the IR and ${ }^{1} \mathrm{H}$ NMR spectroscopy. In the IR spectrum of the polymer film, the absorption peak at $992 \mathrm{~cm}^{-1}$ assignable to the cyclic $\mathrm{C}-\mathrm{O}-\mathrm{C}$ stretching from oxetane ring decreased, and showed a new appearance of characteristic absorption peaks at 3438 $\mathrm{cm}^{-1}$ assignable to the pendant $\mathrm{OH}$ group, and at 1729 , and $1241 \mathrm{~cm}^{-1}$ assignable to the $\mathrm{C}=\mathrm{O}$ and $\mathrm{C}-$ $\mathrm{O}-\mathrm{C}$ (ester) stretching from alkyl ester linkage, respectively. The ${ }^{1} \mathrm{H}$ NMR spectrum of this polymer showed signals at $\delta=0.74-0.85$ due to $-\mathrm{CH}_{2}-\mathrm{C}_{3}$, 1.37-1.64 due to $-\mathrm{CH}_{2} \mathrm{CH}_{3}, 3.31-3.53$ due to $\mathrm{O}-$ $\mathrm{C}_{2}-\mathrm{C}$ and $\mathrm{C}_{2}-\mathrm{OH}, 4.23-4.53$ due to $\mathrm{CO}_{2}-\underline{\mathrm{C}}_{2}-$ $\mathrm{C}, \mathrm{Ar}-\mathrm{CH}_{2}-\mathrm{O}, \mathrm{C}-\mathrm{CH}_{2}-\mathrm{O}$ in oxetane ring, and $\mathrm{CH}_{2}-$ $\mathrm{OH}, 7.12-7.34$ due to aromatic protons in BEOB unit, and 8.51-8.69 ppm due to aromatic protons in TMA unit (Figure 1). Furthermore, many terminal carboxyl groups were confirmed by neutralization titration. From these analytical data, although the degree of

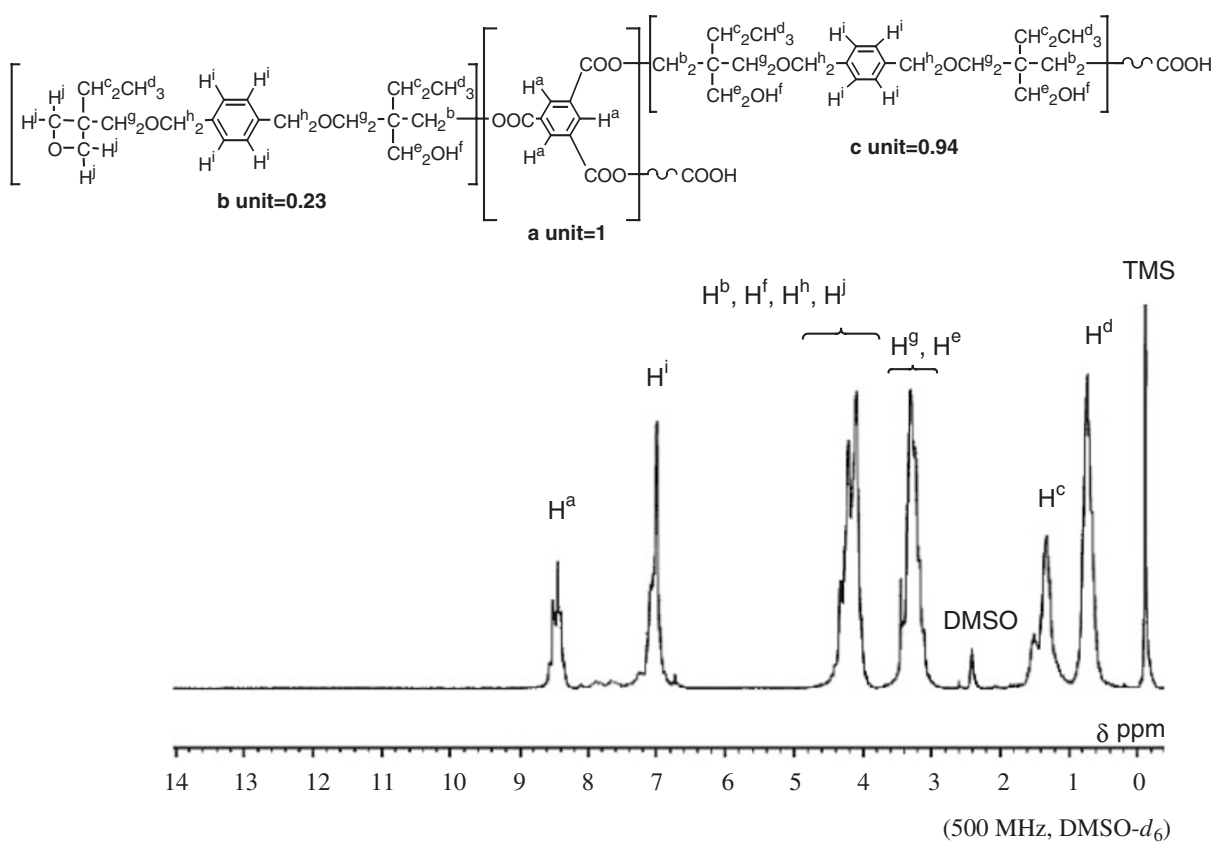

Figure 1. ${ }^{1} \mathrm{H}$ NMR spectrum of hyperbranched polymer P-1. 


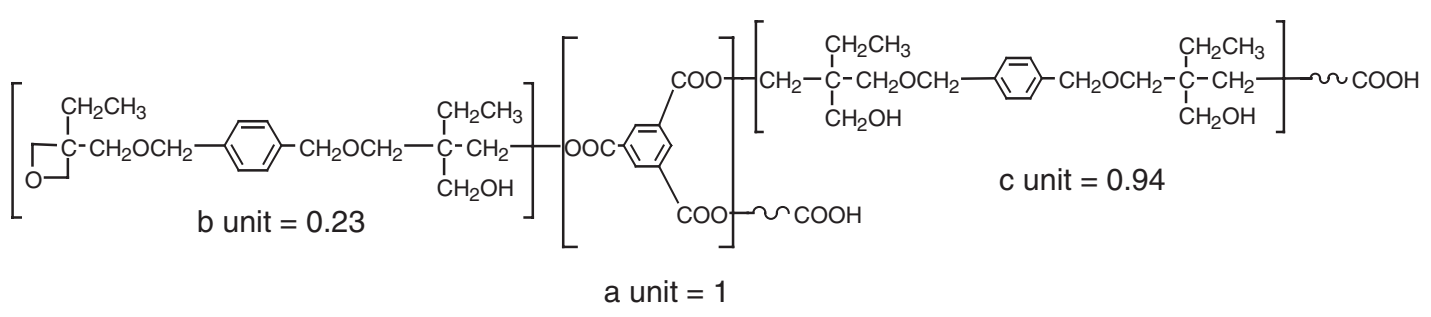

Figure 2. The structure of hyperbranched polymer P-1.

Table II. The polyaddition of BEOB with TMA in certain solvents ${ }^{\mathrm{a}}$

\begin{tabular}{clccc}
\hline Run & \multicolumn{1}{c}{ Solvent } & Yield $(\%)^{\mathrm{b}}$ & $M_{\mathrm{n}} \times 10^{-3 \mathrm{c}}$ & $M_{\mathrm{w}} / M_{\mathrm{n}} \mathrm{c}$ \\
\hline 1 & None & - & - & - \\
2 & Anisole & - & - & - \\
3 & $o$-Dichlorobenzene & - & - & - \\
4 & DMSO & 37 & 4.2 & 1.86 \\
5 & DMAc & 80 & 5.7 & 2.49 \\
6 & NMP & 84 & 8.5 & 2.89 \\
7 & HMPA & 83 & 9.3 & 5.28 \\
8 & Sulfolane & $81(15)$ & 14.2 & 20.39 \\
\hline
\end{tabular}

${ }^{\mathrm{a}}$ The reaction was carried out with BEOB $(1.5 \mathrm{mmol})$ using $5 \mathrm{~mol} \%$ of TPPC in various solvent at $140^{\circ} \mathrm{C}$ for $12 \mathrm{~h}$. ${ }^{\mathrm{b}}$ Insoluble parts in water and $n$-hexane and diethyl ether. ${ }^{c}$ Estimated by GPC (DMF) based on polystyrene standards. ${ }^{\mathrm{d}}$ Insoluble parts in THF.

branching of the resulting polymer could not be calculated, we can suggest the following repeating units such as $\mathbf{a}=0.23$ and $\mathbf{c}=0.94$ of the polymer structure based on the value $\mathbf{b}=1.0$ (Figure 2).

We examined the effect of reaction medium under the same conditions using TPPC as the catalyst, which has the highest activity. As summarized in Table II, the polyaddition of BEOB with TMA proceeded in DMSO, DMAc, NMP, and HMPA to give the soluble polymers (Table II). This suggests that the yields and $M_{\mathrm{n}}$ of the resulting polymers increased with dipole moment of the used aprotic polar solvents excepting DMSO. ${ }^{31}$ However, $81 \mathrm{wt} \%$ of soluble polymer and $15 \mathrm{wt} \%$ of insoluble gel products were obtained from the reaction in sulfolane, which had very high dipole moment among them. On the other hand, no reaction occurred in anisole and $o$-dichlorobenzene, and in bulk, because TMA was insoluble in these solvent and BEOB under this reaction condition.

This means that NMP is a suitable reaction solvent for the polyaddition of BEOB with TMA to afford corresponding hyperbranched polyester containing many pendant hydroxy groups.

We also examined the effect of reaction temperature and the time using TPPC in NMP. As shown in Figure 3, although no reaction occurred at $100^{\circ} \mathrm{C}$ for $12 \mathrm{~h}$, the yields and $M_{\mathrm{n}} \mathrm{s}$ of soluble hyperbranched polymers increased gradually with temperatures at

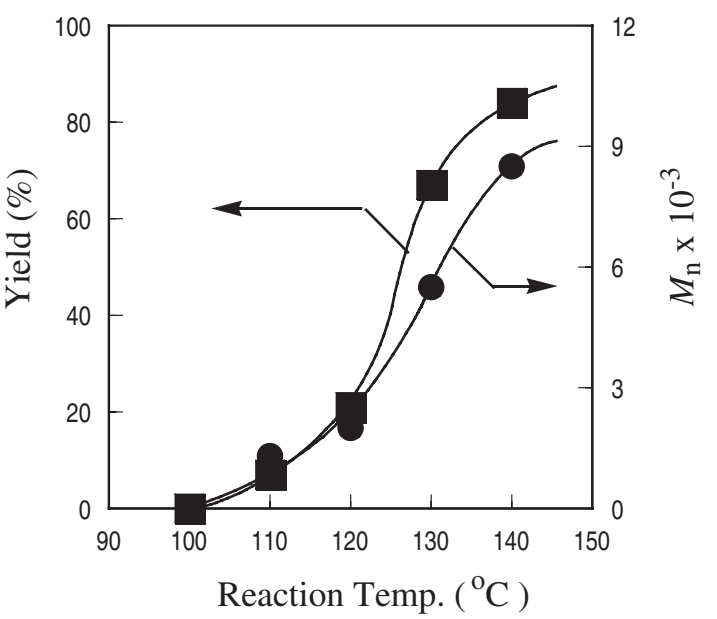

Figure 3. Effect of reaction temperature on the polyaddition of BEOB with TMA. The reaction was carried out with BEOB $(1.5 \mathrm{mmol})$ with TMA $(1.0 \mathrm{mmol})$ using TPPC $(5 \mathrm{~mol} \%)$ as the catalyst in NMP $(1.0 \mathrm{~mL})$ for $12 \mathrm{~h} .(\bullet): M_{\mathrm{n}},(\mathbf{\square})$ : Yield.

$110-140^{\circ} \mathrm{C}$ for $12 \mathrm{~h}$. However, when the polyaddition was performed at $150^{\circ} \mathrm{C}$ for $12 \mathrm{~h}, 84 \mathrm{wt} \%$ of insoluble gel products and $14 \mathrm{wt} \%$ of soluble products were obtained. In addition, the molecular weight distribution $\left(M_{\mathrm{w}} / M_{\mathrm{n}}\right)$ of the obtained soluble products in this reaction was 26.06. Therefore, it seems that $140^{\circ} \mathrm{C}$ was suitable reaction temperature to obtain soluble hyperbranched polymer in good yields under this reaction condition.

As shown in Figure 4, the yields and $M_{\mathrm{n}}$ of the soluble polymers increased with reaction time at 3$15 \mathrm{~h}$ when the polyaddition of BEOB with TMA was carried out at $140{ }^{\circ} \mathrm{C}$ in NMP using TPPC as a catalyst. However, $63 \mathrm{wt} \%$ of insoluble gel products and $31 \mathrm{wt} \%$ of soluble products were obtained when the reaction was performed for $18 \mathrm{~h}$. It was also found that the molecular weight distribution of the obtained soluble polymers broadened with reaction time. This shows that reaction temperature and time are important factor to obtain soluble hyperbranched polymers in good yields.

The effect of feed ratio of TMA was examined at $140^{\circ} \mathrm{C}$ for $12 \mathrm{~h}$ in NMP using $5 \mathrm{~mol} \%$ of TPPC as the catalyst. As summarized in Table III, hyperbranched polymer with the highest molecular weight 

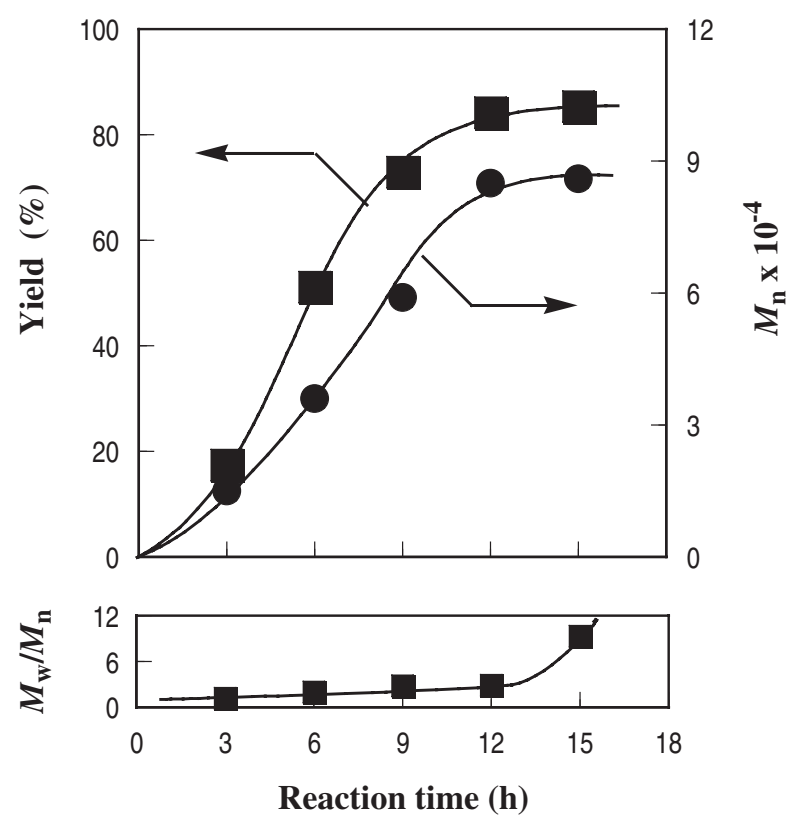

Figure 4. Effect of reaction time on the polyaddition of BEOB with TMA. The reaction was carried out with BEOB $(1.5 \mathrm{mmol})$ with TMA $(1.0 \mathrm{mmol})$ using TPPC $(5 \mathrm{~mol} \%)$ as the catalyst in NMP $(1.0 \mathrm{~mL})$ at $140^{\circ} \mathrm{C} .(\bullet): M_{\mathrm{n}},(\boldsymbol{\square})$ : Yield. was obtained, when the reaction was performed with equivalent molar ratio of BEOB with TMA, and it was found that the molecular weights decreased with increasing or decreasing TMA. It is also suggested that $\mathbf{b}$ unit contents increased with increasing feed ratio of BEOB, and carboxyl group contents increased with increasing feed ratio of TMA under this reaction condition.

From the above information, polyadditions of other bis(oxetane)s such as 1,2-BEOMB, 1,3-BEOMB, 1,4BEOMB, 4,4'-BEOBP, and TM-BEOBP with TMS were examined using $5 \mathrm{~mol} \%$ of TPPC as a catalyst in DMAc at $140^{\circ} \mathrm{C}$ for $24 \mathrm{~h}$, and all the results are summarized in Table IV. Polyadditions of 4,4'BEOBP and TM-BEOBP with TMA produced corresponding hyperbranched polymers (P-5, P-6) with relatively high molecular weights in satisfactory yields, respectively. However, the yields and molecular weights of P-2, P-3, and P-4 were not high enough by the polyadditions of BEOMBs with TMA, respectively.

Glass transition temperatures $\left(T_{\mathrm{g}}\right) \mathrm{s}$ and weight loss temperatures $\left(T_{\mathrm{d}}\right) \mathrm{s}$ of the synthesized polymers $\mathbf{P}-\mathbf{1}-$

Table III. Effect of feed ratio of TMA on the polyaddition with BEOB ${ }^{\mathrm{a}}$

\begin{tabular}{|c|c|c|c|c|c|c|}
\hline \multirow{2}{*}{ Run } & \multirow{2}{*}{ TMA (mmol) } & \multirow{2}{*}{ Yield $(\%)^{\mathrm{b}}$} & \multirow{2}{*}{$M_{\mathrm{n}} \times 10^{-3 \mathrm{c}}$} & \multirow{2}{*}{$M_{\mathrm{w}} / M_{\mathrm{n}}^{\mathrm{c}}$} & Unit ratio $^{\mathrm{d}}$ & \multirow{2}{*}{$\mathrm{COOH}(\%)$} \\
\hline & & & & & $a: b: c$ & \\
\hline 1 & 0.5 & 48 & 4.9 & 1.63 & 1:0.71:1.18 & 1.52 \\
\hline 2 & 0.7 & 49 & 5.2 & 2.02 & 1:0.42:0.98 & 2.17 \\
\hline 3 & 0.9 & 73 & 6.7 & 1.97 & 1:0.38:0.98 & 4.01 \\
\hline 4 & 1.0 & 84 & 8.5 & 2.89 & $1: 0.23: 0.95$ & 4.81 \\
\hline 5 & 1.1 & 81 & 8.0 & 2.29 & 1:0.20:0.98 & 5.38 \\
\hline 6 & 1.3 & 62 & 7.0 & 3.04 & 1:0.19:0.94 & 6.18 \\
\hline 7 & 1.5 & 52 & 5.9 & 2.99 & 1:0.06:0.60 & 7.54 \\
\hline
\end{tabular}

${ }^{\text {a }}$ The reaction was carried out with BEOB $(1.5 \mathrm{mmol})$ and TMA using $5 \mathrm{~mol} \%$ of TPPC in various sol-

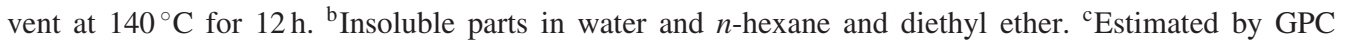
(DMF) based on polystyrene standards. ${ }^{\mathrm{d}}$ Estimated by ${ }^{1} \mathrm{H}$ NMR. ${ }^{\mathrm{e}}$ Estimated by titration of carboxyl groups in polymer.

Table IV. The polyaddition of certain bis(oxetane)s with TMA ${ }^{\mathrm{a}}$

\begin{tabular}{ccccccrc}
\hline Run & Polymer & $\begin{array}{c}\text { Yield } \\
(\%)^{\mathrm{b}}\end{array}$ & $M_{\mathrm{n}} \times 10^{-3 \mathrm{c}}$ & $M_{\mathrm{w}} / M_{\mathrm{n}}{ }^{\mathrm{c}}$ & $\begin{array}{c}\mathrm{COOH} \\
(\%)^{\mathrm{d}}\end{array}$ & $\begin{array}{c}T_{\mathrm{g}} \\
\left({ }^{\circ} \mathrm{C}\right)^{\mathrm{e}}\end{array}$ & $T_{\mathrm{d}}{ }^{5 \% \mathrm{f}}$ \\
\hline 1 & $\mathbf{P}-1$ & 84 & 8.5 & 2.89 & 4.81 & 59 & 331 \\
2 & $\mathbf{P}-2$ & 21 & 2.4 & 1.34 & 4.31 & 77 & 328 \\
3 & $\mathbf{P - 3}$ & 49 & 3.0 & 1.37 & 4.41 & 78 & 321 \\
4 & $\mathbf{P}-4$ & 53 & 4.1 & 1.70 & 4.14 & 84 & 335 \\
5 & $\mathbf{P - 5}$ & 74 & 6.2 & 1.74 & 3.77 & 131 & 376 \\
6 & $\mathbf{P - 6}$ & 79 & 6.9 & 2.14 & 4.16 & 120 & 348 \\
\hline
\end{tabular}

${ }^{\text {a }}$ The reaction was carried out with Bis(oxetane) $(1.5 \mathrm{mmol})$ and TMA $(1 \mathrm{mmol})$ using $5 \mathrm{~mol} \%$ of TPPC in NMP $1.5 \mathrm{~mL}$ at $140{ }^{\circ} \mathrm{C}$ for $12 \mathrm{~h} .{ }^{\mathrm{b}}$ Insoluble parts in water and $n$-hexane and diethyl ether. ${ }^{\mathrm{c}}$ Estimated by GPC (DMF) based on polystyrene standards. ${ }^{\mathrm{d}}$ Estimated by titration of carboxy group in polymer. ${ }^{\mathrm{e}}$ Determined by DSC at heating rate $10{ }^{\circ} \mathrm{C} / \mathrm{min}$ in nitrogen. ${ }^{\mathrm{f}}$ Determined by TG/DTA at heating rate $10^{\circ} \mathrm{C} / \mathrm{min}$ in nitrogen. 
Table V. Solubility of hyperbranched polyesters P-1-P-6

\begin{tabular}{lcccccc}
\hline \multicolumn{1}{c}{ Solvent } & P-1 & P-2 & P-3 & P-4 & P-5 & P-6 \\
\hline Water & - & - & - & - & - & - \\
Hexane & - & - & - & - & - & - \\
Cyclohexane & - & - & - & - & - & - \\
Toluene & - & - & - & - & - & - \\
1,4-Dioxane & ++ & ++ & ++ & ++ & ++ & ++ \\
Diethyl ether & - & - & - & - & - & - \\
Chloroform & ++ & ++ & ++ & ++ & ++ & ++ \\
Anisole & - & + & + & + & - & - \\
Chlorobenzene & - & - & - & - & - & - \\
Methanol & ++ & ++ & ++ & ++ & - & - \\
Ethanol & ++ & ++ & ++ & ++ & - & - \\
THF & ++ & ++ & ++ & ++ & ++ & ++ \\
Ethyl acetate & - & - & - & - & - & - \\
$o$-Dichlorobenzene & - & - & - & - & - & - \\
Acetone & ++ & ++ & ++ & ++ & ++ & ++ \\
Acetonitrile & - & - & - & - & - & - \\
MEK & ++ & ++ & ++ & ++ & ++ & ++ \\
DMAc & ++ & ++ & ++ & ++ & ++ & ++ \\
DMF & ++ & ++ & ++ & ++ & ++ & ++ \\
NMP & ++ & ++ & ++ & ++ & ++ & ++ \\
DMSO & ++ & ++ & ++ & ++ & ++ & ++ \\
HMPA & ++ & ++ & ++ & ++ & ++ & ++ \\
1 wt \% Na $\mathrm{CO}_{3}$ aq. & +- & +- & +- & +- & +- & +- \\
2.38 wt \% TMAH & ++ & ++ & ++ & ++ & ++ & ++ \\
\hline
\end{tabular}

${ }^{a}++$; soluble at room temperature. + ; soluble by heating. +- ; partially soluble or swelling. - ; insoluble.

P-6 were measured by DSC and TGA, respectively. As summarized in Table IV, P-5 and P-6 composed from BEOBP unit showed high $T_{\mathrm{g}} \mathrm{s}$ such as 131 and $120^{\circ} \mathrm{C}$, respectively. On the other hand the $T_{\mathrm{g}}$ of P-1 prepared from relatively flexible unit BEOB was $59^{\circ} \mathrm{C}$. Polymers P-2, P-3, and $\mathbf{P}-\mathbf{4}$ prepared from BEOMB unit showed $T_{\mathrm{g}} \mathrm{s}$ at 77,78 , and $84^{\circ} \mathrm{C}$, respectively. This result shows that the $T_{\mathrm{g}} \mathrm{s}$ of the obtained hyperbranched polyesters were strongly affected by the structure of the repeating units.

Furthermore, we examined $5 \mathrm{wt} \%$ loss temperatures $\left(T_{\mathrm{d}}{ }^{5 \%}\right)$ of all the obtained hyperbranched polymers. As summarized in Table IV, $T_{\mathrm{d}}{ }^{5 \%}$ of $\mathbf{P - 5}$ and P-6 were 376 and $348^{\circ} \mathrm{C}$, respectively, which are higher than those of P-1, P-2, P-3, and P-4. On the other hand, $T_{\mathrm{d}}{ }^{5 \%}$ of $\mathbf{P}-\mathbf{1}, \mathbf{P}-\mathbf{2}, \mathbf{P}-\mathbf{3}$, and $\mathbf{P}-\mathbf{4}$ were $331,328,321$, and $335^{\circ} \mathrm{C}$, respectively. This result suggests that the thermal decomposition temperatures of the hyperbranched polyesters were also strongly influenced by the molecular structure of the repeating units. Consequently, both $T_{\mathrm{g}}$ and thermal stability of the hyperbranched polymers containing biphenyl moieties as repeating units were higher than those of other hyperbranched polymers.

All the obtained hyperbranched polyesters P-1-P-6 containing many pendant primary hydroxy groups were insoluble in water. However, interestingly enough, it was found that these polymers were well soluble in $2.38 \%$ TMAH aqueous solution, and partly soluble or swelling in $1 \%$ sodium carbonate aqueous solution. These polymers also showed characteristic solubility to organic solvents. That is, although these polymers were ordinarily insoluble in aromatic solvents, $n$-hexane, cyclohexane, diethyl ether, and acetonitrile, and were soluble in chloroform, THF, MEK, and aprotic polar solvents such as DMF, DMAc, NMP, DMSO, and HMPA. Furthermore, polymers P-1-P-4 were soluble in methanol and ethanol. However, polymers P-5 and P-6 were insoluble in the alcohols. That is, the solubility of the obtained hyperbranched polyesters was strongly influenced by the polymer structure.

\section{CONCLUSIONS}

We demonstrated the synthesis of the novel hyperbranched poly(ester)s containing many pendant primary hydroxy groups by the polyaddition of bis(oxetane)s and TMA. The reaction of bis(oxetane)s with TMA proceeded smoothly using tetraphenylphosphonium halides as catalysts at $140^{\circ} \mathrm{C}$ for $12 \mathrm{~h}$ in NMP, affording the corresponding hyperbranched poly(ester)s. The certain characteristic properties such as thermal properties and solubility of the synthesized hyperbranched polymers were evaluated, and it was found that these properties were strongly influenced by their structures. Furthermore, it is expected that the synthesized hyperbranched polymers are useful functional materials.

\section{REFERENCES}

1. A. S. Pell and G. Pilchere, Trans. Faraday Soc., 61, 71 (1965).

2. S. Inoue and T. Aida, "Ring-Opening Polymerization," K. J. Ivin and T. Saegusa, Ed., Elsevior Science Publishers, London, 1984, p 185.

3. A. Ueyama, M. Mizuno, S. Kanoh, and M. Motoi, Polym. J., 34, 944 (2002).

4. S. Kano, T. Nishimura, Y. Kita, H. Ogawa, M. Motoi, M. Takani, and T. Tanaka, J. Org. Chem., 65, 2253 (2000).

5. H. Ogawa, S. Kanoh, and M. Motoi, Bull. Chem. Soc. Jpn., 70, 1649 (1997).

6. T. Nishikubo and A. Kameyama, Kagaku to Kogyo, 57, 225 (2004).

7. T. Nishikubo and K. Sato, Chem. Lett., 697 (1991).

8. S. Minegishi, S. Tsuchida, M. Sasaki, A. Kameyama, and T. Nishikubo, J. Polym. Sci., Part A: Polym. Chem., 40, 3835 (2002).

9. S. Minegishi, M. Ito, A. Kameyama, and T. Nishikubo, J. Polym. Sci., Part A: Polym. Chem., 38, 2254 (2000).

10. T. Nishikubo, A. Kameyama, and A. Suzuki, React. Funct. 
Polym., 37, 19 (1998).

11. T. Nishikubo, A. Kameyama, M. Ito, T. Nakajima, and H. Miyazaki, J. Polym. Sci., Part A: Polym. Chem., 37, 2781 (1999).

12. Y. Konno, H. Suzuki, H. Kudo, A. Kameyama, and T. Nishikubo, Polym. J., 36, 114 (2004).

13. T. Nishikubo, A. Kameyama, M. Ito, and A. Suzuki, J. Polym. Sci., Part A: Polym. Chem., 36, 2873 (1998).

14. A. Kameyama, Y. Yamamoto, and T. Nishikubo, J. Polym. Sci., Part A: Polym. Chem., 31, 1639 (1993).

15. A. Kameyama, Y. Yamamoto, and T. Nishikubo, Macromol. Chem. Phys., 197, 1147 (1996).

16. T. Nishikubo, A. Kameyama, and C. Izawa, J. Polym. Sci., Part A: Polym. Chem., 39, 368 (2001).

17. T. Yashiro, K. Matsushima, A. Kameyama, and T. Nishikubo, Macromolecules, 33, 7737 (2000).

18. H. Kudo, T. Kurakata, M. Sasaki, and T. Nishikubo, $J$. Polym. Sci., Part A: Polym. Chem., 42, 1528 (2004).

19. T. Nishikubo, H. Kudo, M. Sasaki, K. Kuwamura, and C. Imataki, Polym. J., 36, 841 (2004).

20. H. Kudo, A. Morita, and T. Nishikubo, Polym. J., 35, 88 (2003)

21. A. Morita, H. Kudo, and T. Nishikubo, Polym. J., 36, 413
(2004).

22. A. Morita, H. Kudo, and T. Nishikubo, J. Polym. Sci., Part A: Polym. Chem., 42, 3739 (2004).

23. A. Kameyama, K. Ueda, H. Kudo, and T. Nishikubo, Macromolecules, 35, 3792 (2002).

24. M. Okazaki, I. Washio, Y. Shibasaki, and M. Ueda, J. Am. Chem. Soc., 125, 8120 (2003).

25. K. Matyjaszewski, S. G. Gaynor, A. Kulfan, and M. Podwike, Macromolecules, 30, 5192 (1997).

26. A. Sunder, R. Hanselmann, H. Frey, and R. Mulhaupt, Macromolecules, 32, 4240 (1999).

27. J. Hao, M. Jikei, and M. Kakimoto, Macromolecules, 36, 3519 (2003).

28. S. Makita, H. Kudo, and T. Nishikubo, J. Polym. Sci., Part A: Polym. Chem., 42, 3697 (2004).

29. T. Nishikubo, T. Iizawa, M. Shimojyo, T. Kato, and A. Shiina, J. Org. Chem., 55, 2536 (1990).

30. T. Nishikubo, T. Kato, Y. Sugimoto, M. Tomoi, and S. Ishigaki, Macromolecules, 23, 3406 (1990).

31. "Handbook of Solvents," T. Asahara, N. Tokura, M. Okawara, J. Kumanotani, and M. Seno, Ed., Kodansha, Tokyo, 1976. 